\title{
Ag-TiO 2 Assisted Photocatalytic Degradation of Cytostatic Drug Cyclophosphamide Under UV-VIS Light
}

\author{
IONUT NICOLAE CRISTEA ${ }^{1}$, ARCADIE SOBETKII ${ }^{2}$, \\ LUCIAN ALEXANDRU CONSTANTIN ${ }^{1}$, MIRELA ALINA CONSTANTIN ${ }^{1}$, INES NITOI $^{1}$ \\ ${ }^{1}$ National Research and Development Institute for Industrial Ecology - ECOIND, 71-73 Drumul Podu Dambovitei Str., 060652, \\ Bucharest, Romania \\ ${ }^{2}$ SC.MGM STAR CONSTRUCT S.R.L., 7 Pancota Str., Bl.13, Apt.19, 022773, Bucharest, Romania
}

\begin{abstract}
Cyclophosphamide (CP) is a commonly prescribed cytostatic drug that has cytotoxic, genotoxic, mutagenic, carcinogenic and teratogenic effects on living organisms, which asks for its elimination from any water source. The photocatalytic degradation of CP under UV-VIS irradiation was studied, using non-doped $\mathrm{TiO}_{2}$ and $\mathrm{Ag}$-doped $\mathrm{TiO}_{2}$ (0.5-1.7\% wt.). The catalysts were synthesized by vacuum deposition method. The influence of Ag concentration on the degradation performance of $\mathrm{CP}$ was investigated and an optimal content of $1.0 \% \mathrm{Ag}$ was established. Using of this catalyst assures the pollutant degradation with a rate constant $k_{C P}=6.59 \times 10^{-4} \mathrm{~s}^{-1}$ and an efficiency $\eta_{C P}=99 \%$ after120 min irradiation time. Based on the results of the quenching experiments in the presence of suitable scavengers, a mechanism of photocatalytic degradation of CP has been proposed. This consists in the attack of free hydroxyl radicals and superoxide radicals on the pollutant. Also, the contribution of Ag to inhibition of charge recombination and the additional generation of superoxide radicals, which are responsible for the higher photocatalytic activity of $\mathrm{Ag}$ doped $\mathrm{TiO}_{2}$ compared to non-doped $\mathrm{TiO}_{2}$, was emphasised.
\end{abstract}

Keywords: Cyclophosphamide, un-doped $\mathrm{TiO}_{2}$, Ag-doped $\mathrm{TiO}_{2}$, photocatalysis, reactive species

\section{Introduction}

Cytostatic drugs used in chemotherapy represent emerging pollutants which can affect quality of surface water that are receiving urban wastewater treatment plants (WWTPs)effluents. These pollutants reach the sewage through hospital effluents and domestic wastewater discharged.

Due to their specific characteristics (polar character, relative high water solubility and low absorption of sunlight with $\lambda>290 \mathrm{~nm}$ ) many of these pollutants are poorly photolytic converted under sunlight, weak biodegradable and not fully metabolised. These are the main reasons why cytostatic drugs resist to classical physical-chemical and biological processes applied within WWTPs [1].

The cytostatic drugs concentration in water bodies depends on their type and consumption level. In the case of cyclophosphamide (CP), compound belonging to oxazaphosphorines class which is one of the most commonly prescribed antineoplastic drug, the reported concentration in water and water bodies is usually under $30 \mathrm{ng} / \mathrm{L}$ in EU countries [2-6], excepting Romania which identified CP concentration twice higher in Somes river [7]. Anyway, the concentration level is in good correlation with statistic data regarding $\mathrm{CP}$ consumption, which in UE member states is around hundreds $\mathrm{kg} /$ years/country [8].

Since CP, like other cytostatic drugs, is intended to disrupt or prevent cellular growth, it presents potential cytotoxic, genotoxic, mutagenic, carcinogenic, and teratogenic effects on living organisms. For these reasons, cytostatic drugs should be removed from water.

Application of advanced oxidation processes (AOPs) may be a possible solution of this problem. There are examples about antineoplastics removal from various water sources by ozonation [9], $\mathrm{H}_{2} \mathrm{O}_{2}$

\footnotetext{
*email: ionut.cristea@incdecoind.ro
} 
assisted photolysis, photo-Fenton process [10] and photocatalysis assisted by commercial $\mathrm{TiO}_{2}$ [1113]. The reported data reveals that efficient pollutant degradation occurs in optimum working conditions ( $\mathrm{pH}, \mathrm{H}_{2} \mathrm{O}_{2}$ and $\mathrm{Fe}^{2+}$ concentrations, $\mathrm{TiO}_{2}$ dose, cytostatic drug concentration, and irradiation time).

Although, $\mathrm{TiO}_{2}$ photocatalyst presents many advantages like: enhanced chemical stability, low toxicity, and relatively low cost [14], it is photoactive only under UV irradiation, due to its large band gap energy (3.2eV for anatase). Another drawback of pristine titania is related to fast recombination of photo-generated electrons and holes which has as result the decrease of oxidizing reactive species concentration with negative impact upon pollutant degradation efficiency. In order to solve these problems a lot of scientific work has been reported within the following research directions:

- shifting the $\mathrm{TiO}_{2}$ photoactivity to the visible(VIS) range by doping of semiconductors with non-metals (N and S) [15-17];

- inhibition of charges recombination by doping of semiconductors with heavy metals like Fe, $\mathrm{Ni}, \mathrm{Co}, \mathrm{Cr}, \mathrm{V}$ [18-22].

Besides these strategies, addition of noble metals like Pt and $\mathrm{Ag}$ to pristine $\mathrm{TiO}_{2}[23,24]$ has been proved to be an effective method to improve photocatalytic activity due to fact that noble metals act as traps for photo-generated electrons( $\left.\mathrm{e}^{-}\right)$and inhibit their recombination with holes $\left(\mathrm{h}^{+}\right)$. On the other hand, noble metals nano-particles present strong absorption in visible range and can improve sunlight photo-excitation of doped titania which assures the decrease of energy consumption and cost reduction.

Among noble metals doped titania only $\mathrm{Pt}_{-} \mathrm{TiO}_{2}$ has been the subject of some systematic studies on $\mathrm{CP}$ photocatalytic degradation [25]. The results showed that $\mathrm{Pt}-\mathrm{TiO}_{2}$ assures a 5 times increase of rate constant, compared withpristineTiO ${ }_{2}$.

Although, photocatalytic activity of Ag doped titania is less enhanced compared with Pt doped catalyst, Ag is most suitable for industrial application due to its low cost and easy preparation [26]. In addition, Ag has special behaviour related to oxygen adsorption and photocatalytic pollutant degradation is an oxidation processes controlled by the charge transfer to $\mathrm{O}_{2}$.

In this paper we present results concerning $\mathrm{Ag}$ - doped $\mathrm{TiO}_{2}$ assisted photocatalytic degradation of CP under UV-VIS light, a topic still not approached according to our knowledge. The photocatalytic activity of Ag-doped $\mathrm{TiO}_{2}$ was compared with un - doped $\mathrm{TiO}_{2}$ and the influence of $\mathrm{Ag}$ content on $\mathrm{CP}$ photocatalytic degradation efficiency and kinetics were studied. All catalysts were synthesised by vacuum deposition method. The identification of reactive species involved in $\mathrm{CP}$ photocatalytic conversion was also investigated by quenching experiments performed in the presence of hydroxyl radicals, superoxide radicals and holes scavengers, in order to elucidate the mechanism of pollutant degradation on $\mathrm{Ag}$ - doped $\mathrm{TiO}_{2}$.

\section{Experimental part}

\subsection{Materials}

The following reagents were used: Cyclophosphamide (Alfa Aesar) 97\% purity; Trifluoroacetic anhydride (Sigma Aldrich) 99\% purity, Toluene (Merck) GC-MS grade, Sodium chloride (Chempur) 99,5\% purity, Sodium sulphate anhydrous (Chempur) $99 \%$ purity.

The following reagents were used as scavengers for reactive species: Isopropanol (J.T.Baker) ACS grade, Sodium fluoride (Chempur) $99 \%$ purity, Ethylenediaminetetraacetate disodium salt (Merck) 98.5\% purity, Benzoquinone (Sigma Aldrich) $98 \%$ purity.

All aqueous solutions were prepared using ultrapure water generated by a MilliQ Integral 15 equipment.

Un-doped $\mathrm{TiO}_{2}$ and $\mathrm{Ag}$-doped $\mathrm{TiO}_{2}$ with various metal concentrations $(0.5-1.7 \mathrm{wt} \%)$ catalysts (synthesised by SC MGM STAR CONSTRUCT SRL) were used. Each of them has been deposited as thin film $(300 \mathrm{~nm})$ on glass plate with $14 \mathrm{~cm}^{2}$ area. 


\subsection{Experimental set-up}

The photodegradation experiments were performed using a batch reactor with medium-pressure mercury lamp TQ-150-Z3 which emits radiation in the domain $\lambda=320-500 \mathrm{~nm}$. The lamp equipped with an glass water cooling jacket and 6 plates of catalyst placed equidistantly around the light source were immersed in the centre of the reactor $(\mathrm{V}=1000 \mathrm{~mL})$ containing the $\mathrm{CP}$ solution. The determination of photon's flow of emitted radiations was performed by chemical actinometry using ferrioxalate solution and a value of $\mathrm{I}_{0}=1.05 \times 10^{-6}$ einstein $\mathrm{s}^{-1}$ was registered. Using various catalysts, solution with $0.04 \mathrm{mM} \mathrm{CP}$ content was photo-oxidized in the following working conditions: $\mathrm{pH}=8.5$; catalyst total irradiation area $=84 \mathrm{~cm}^{2}$; irradiation time $=30-120$ minutes. Prior to irradiation $(30$ min.) and during photocatalysis experiments, air was bubbled into solution at 50L/h flow.

All experiments were duplicated in order to assure data quality.

\subsection{Analytical method}

In order to assess the efficiencies of pollutant degradation, initial and irradiated samples were analysed for CP concentration by gas chromatography coupled with ion trap mass spectrometry(GCITMS) using an Agilent 7890A - Agilent 240MS equipment. Volumes of $10 \mathrm{~mL}$ of samples were saturated with sodium chloride. The samples $\mathrm{pH}$ was adjusted to 10 by addition of $0.5 \mathrm{~mL}$ of $1 \mathrm{M}$ ammonia buffer solution. The treated samples were extracted with 2-5 $\mathrm{mL}$ of toluene. Organic extract was dried with anhydrous $\mathrm{Na}_{2} \mathrm{SO}_{4} .1 \mathrm{~mL}$ of extract was placed in $2 \mathrm{~mL}$ GC vial and then $10 \mu \mathrm{L}$ of trifluoroacetic anhydride was added. After sealing and shaking the vials were heated at $70^{\circ} \mathrm{C}$ for $2 \mathrm{~h}$. After cooling, $1 \mu \mathrm{L}$ of treated samples were injected and analysed by GC-ITMS. For separation, low polarity phase column ( $5 \%$ diphenyl/95\% dimethyl polysiloxane, $30 \mathrm{~m}, 0.25 \mathrm{~mm}$ ID, $0.25 \mu \mathrm{m}$ film) was used. Retention time for CP derivative was $11.02 \mathrm{~min}, \mathrm{GC}$ conditions were: split injection (1:10) with injector temperature $280^{\circ} \mathrm{C}$, flow rate: $2 \mathrm{~mL} / \mathrm{min}$; carrier gas: helium 6.0 ; temperature ramp employed: $50^{\circ} \mathrm{C}(1 \mathrm{~min}), 20^{\circ} \mathrm{C} / \mathrm{min}$ to $280^{\circ} \mathrm{C}$, hold $3.5 \mathrm{~min}$. Mass detector conditions: Ion Trap: $120^{0}$ C; Manifold: $50^{\circ} \mathrm{C}$; Transfer line: $280^{\circ} \mathrm{C}$; Ion source: $250^{\circ} \mathrm{C}$. Scan mode: single ion monitoring (quantified ion: $\mathrm{m} / \mathrm{z}=307$ and qualifier ion: $\mathrm{m} / \mathrm{z}=309$ ).

\section{Results and discussions}

\subsection{Photocatalytic activity}

The capture of photo-generated electrons can retard electron/hole recombination during irradiation, thus exceeding the lifetime of charge carriers. Doping of $\mathrm{TiO}_{2}$ with heavy or noble metal ions by scattering of metal nano-particles in titania matrix, that acts as electron trap, also assures improvement of photocatalytic activity [27].The photocatalytic activity of un-doped $\mathrm{TiO}_{2}$ and $\mathrm{Ag}-$ doped $\mathrm{TiO}_{2}$ with various noble metal content, was investigated for CP degradation from aqueous solution $(0.04 \mathrm{mM})$. The dopant concentrations, expressed as ratios related to $\mathrm{TiO}_{2}$ were $0.5,1.0$ and $1.7 \mathrm{wt} . \%$. All experiments have been performed in aerobic condition at $\mathrm{pH}=8.5$, for $84 \mathrm{~cm}^{2}$ catalyst total irradiation area and irradiation time between 30-120 min. The efficiency of pollutant degradation was evaluated by determination of $\mathrm{CP}$ concentration vs. irradiation time in treated samples. Kinetic curves recorded for various $\mathrm{Ag}$ content compared with un-doped titania, linearized by a first order kinetic, are presented in Figure 1. 


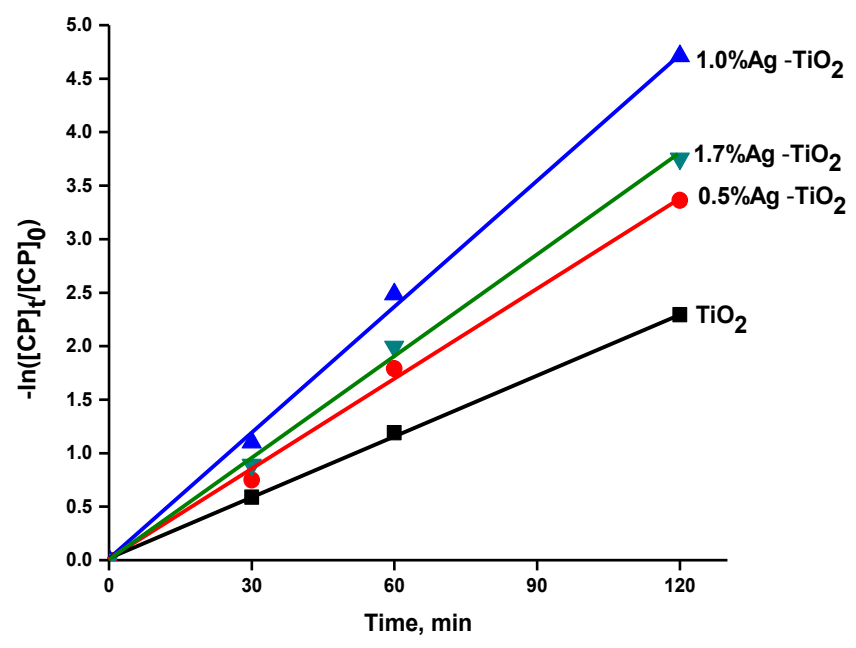

Figure 1. Linearized CP degradation kinetic curves of 0.5-1.7\% Ag-doped $\mathrm{TiO}_{2}$ compared with un-doped $\mathrm{TiO}_{2}$

From the slope of each equation, pseudo-first order rate constants, $\mathrm{k}_{\mathrm{CP}}$ were calculated. Pollutant degradation efficiencies resulted at 120 min. irradiation time and $\mathrm{k}_{\mathrm{CP}}$ values for un-doped and $\mathrm{Ag}$ doped $\mathrm{TiO}_{2}$ with various metal content are presented in Table 1.

Table 1. CP degradation rate constants and efficiencies (120 min) on un-doped and $\mathrm{Ag}$ - doped $\mathrm{TiO}_{2}$ with various dopant content

\begin{tabular}{clll}
\hline Catalyst type & {$[\mathbf{A g}](\mathbf{w t} . \%)$} & $\left.\mathbf{k C P X 1 0} \mathbf{4 s}^{\mathbf{- 1}}\right)$ & $\mathbf{\eta} \mathbf{C P}(\boldsymbol{\%})$ \\
\hline Un-doped $\mathrm{TiO}_{2}$ & - & $3.212 \pm 0.029$ & 89.89 \\
\hline \multirow{3}{*}{ Ag-doped $\mathrm{TiO}_{2}$} & 0.5 & $4.703 \pm 0.098$ & 96.53 \\
\cline { 2 - 4 } & 1.0 & $6.590 \pm 0.102$ & 99.07 \\
\cline { 2 - 4 } & 1.7 & $5.263 \pm 0.084$ & 97.66 \\
\hline
\end{tabular}

Dopant presence within the catalyst matrix assures improvement of $\mathrm{TiO}_{2}$ photocatalytic activity, the values of pollutant degradation rate constants being higher than those obtained for un-doped titania. As experimental results revealed, a relative low Ag content of $1.0 \%$ wt. allows the $\mathrm{CP}$ degradation rate constant increase twice, compared with un-doped $\mathrm{TiO}_{2}$. However, exceeding of this dopant level, considered as optimum, has an opposite effect. Thus, the CP degradation rate constants decreased with $20 \%$, if $\mathrm{Ag}$ concentration is $70 \%$ higher than optimum dopant level.

This behaviour is associated to the change of $\mathrm{e}^{-} / \mathrm{h}^{+}$recombination rate which is influenced by dopant content. It is known that under irradiation, $\mathrm{TiO}_{2}$ is activated and photo-generates $\mathrm{e}^{-} / \mathrm{h}^{+}$pairs. When $\mathrm{Ag}$ is dispersed in semiconductor matrix, electrons in the conduction band of $\mathrm{TiO}_{2}$ can be trapped by Ag nano-particles and inhibit the electrons -holes recombination, because the Fermi level of $\mathrm{TiO}_{2}$ is higher than that of $\mathrm{Ag}$ clusters which became more reductive and behave as accumulation sites of photo-generated electrons transferred from titania. More $\mathrm{Ag}$ loaded in $\mathrm{TiO}_{2}$ matrix increases the number of Ag cluster for electron trapping, which has as result a better charges separation and thus a better photocatalytic activity, as the experimental results showed. However, as more electrons are trapped on Ag clusters, increases the probability that these negative charged sites to become centre for positive charged holes capture. This behaviour affects the electron - holes separation, leading to the decrease of photocatalytic activity. In addition, higher Ag loaded would cover more $\mathrm{TiO}_{2}$ surface and hinder the contact of catalyst with photons and pollutants, which also results in $\mathrm{CP}$ degradation rate constant decreasing, as is showed in the case of $1.7 \% \mathrm{Ag}$-doped $\mathrm{TiO}_{2}$. Based on the experimental 
results assessment it was established that $1 \%$ wt.Ag dopant content assures suitable CP photocatalytic degradation $\left(\eta_{\mathrm{CP}} \geq 99 \%\right)$ after $120 \mathrm{~min}$. irradiation time.

\subsection{Effect of scavenger's presence and degradation mechanism}

In the photocatalytic reactions assisted by catalyst, the main pathways of pollutant degradation are oxidation by direct holes $\left(\mathrm{h}^{+}\right)(\mathrm{Eq} .1)$ and by free and adsorbed hydroxyl radicals generated from interaction between holes and $\mathrm{H}_{2} \mathrm{O}\left({ }^{\circ} \mathrm{OH}\right.$ free, in bulk solution)or $\mathrm{OH}^{-}$ions adsorbed on catalyst surface $\left({ }^{\circ} \mathrm{OH}_{\mathrm{ads}}\right)($ Eqs. 2-4). Another possible oxidation route consists in reaction of pollutant with superoxide radicals $\left(\mathrm{O}_{2}{ }^{-}\right)$generated from electrons (e $\left.\mathrm{e}^{-}\right)$trapping by molecular oxygen (Eqs.5-6) [28].

$$
\begin{aligned}
& h^{+}+\text {Cat-Pollutant } \rightarrow \text { Cat-Degradation Products } \\
& h^{+}+2 \mathrm{H}_{2} \mathrm{O} \rightarrow{ }^{\circ} \mathrm{OH} \text { free (in bulk solution) }+\mathrm{H}_{3} \mathrm{O}^{+} \\
& h^{+}+\mathrm{Cat}-\mathrm{OH} \rightarrow \mathrm{Cat}^{-}{ }^{\circ} \mathrm{OH} \text { ads } \\
& \text { Pollutant }+{ }^{\circ} \mathrm{OH}_{\text {free/ads }} \rightarrow \text { Degradation Products } \\
& e^{-}+\mathrm{O}_{2} \rightarrow \mathrm{O}_{2}{ }^{\cdot}(5) \\
& \mathrm{O}_{2}{ }^{\circ}+\text { Pollutant } \rightarrow \text { Degradation Products }
\end{aligned}
$$

In order to identify any possible contribution of the mentioned reactive species to $\mathrm{CP}$ photocatalytic degradation on Ag-doped $\mathrm{TiO}_{2}$, the influence of suitable scavengers on the cytostatic drug oxidation rate constant was investigated. Quenching experiments were performed on CP solution $(0.04 \mathrm{mM})$ in the presence of following scavengers:

- Disodium ethylenediaminetetracetate (EDTA, 4mM) for trapping of holes;

- Isopropanol (IPR, 4mM) for trapping of free hydroxyl radicals;

- Sodium fluoride (NaF, $2 \mathrm{mM}$ ) for trapping of hydroxyl radicals adsorbed on catalyst surface;

\begin{tabular}{|c|c|c|c|}
\hline Catalyst type & Scavangers type & $\mathrm{k}_{\mathrm{CPX} 10^{4}}\left(\mathrm{~s}^{-1}\right)$ & $\eta_{\mathrm{CP}}(\%)$ \\
\hline \multirow{5}{*}{ Un-doped $\mathrm{TiO}_{2}$} & - & $3.212 \pm 0.029$ & 89.89 \\
\hline & EDTA & $2.933 \pm 0.055$ & 87.60 \\
\hline & IPR & $0.845 \pm 0.018$ & 44.90 \\
\hline & $\mathrm{NaF}$ & $2.792 \pm 0.072$ & 86.20 \\
\hline & BQ & $2.028 \pm 0.035$ & 70.03 \\
\hline \multirow{5}{*}{ Ag-doped $\mathrm{TiO}_{2}$} & - & $6.590 \pm 0.102$ & 99.07 \\
\hline & EDTA & $6.140 \pm 0.070$ & 98.77 \\
\hline & IPR & $2.650 \pm 0.063$ & 84.56 \\
\hline & $\mathrm{NaF}$ & $6.453 \pm 0.083$ & 99.09 \\
\hline & BQ & $3.330 \pm 0.076$ & 90.60 \\
\hline
\end{tabular}

- 1,4-benzoquinone (BQ, $4 \mathrm{mM})$ for trapping of superoxide radicals.

The results of quenching experiments performed on un-doped $\mathrm{TiO}_{2}$ and Ag-doped $\mathrm{TiO}_{2}$ are presented in Table 2 and Figures 2, 3.

Table 2. CP degradation rate constants and efficiencies (120 min) on un-doped and $\mathrm{Ag}$-doped $\mathrm{TiO}_{2}$ in the presence of various reactive species scavengers 


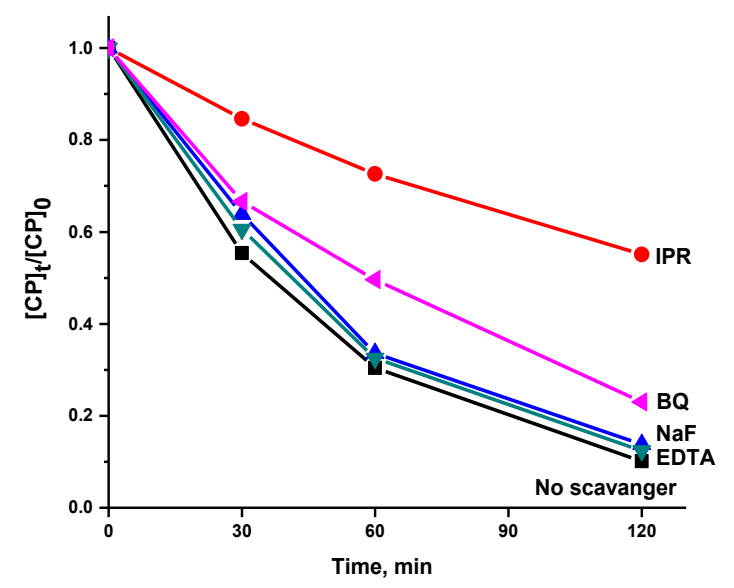

Figure 2. $\mathrm{CP}$ degradation kinetic curves on un-doped $\mathrm{TiO}_{2}$ under

UV-VIS irradiation with and without addition of various reactive species scavengers

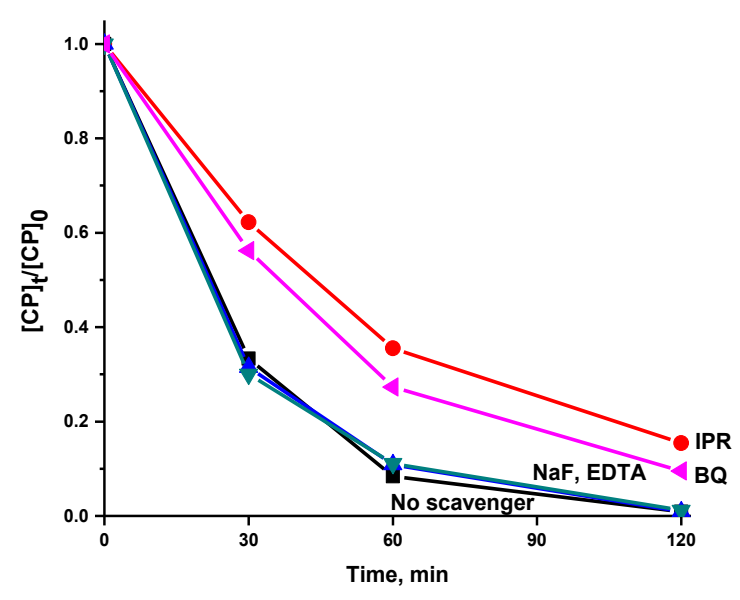

Figure 3. $\mathrm{CP}$ degradation kinetic curves on $1.0 \%$ Ag-doped $\mathrm{TiO}_{2}$ under UV-VIS irradiation with and without addition of various reactive species scavengers

It is known that scavenger presence has as result the decrease of pollutant degradation rate constant due to reactive species quenching. This effect is different for various reactive species, thus the rate constant decrease in the presence of scavenger is more accentuated when a certain reactive species are more involved in the degradation process. In the case of un-doped $\mathrm{TiO}_{2}$, the $\mathrm{CP}$ degradation takes place mainly by free hydroxide radicals, but superoxide radicals has also a contribution. Values of $\mathrm{CP}$ degradation rate constants in the presence of IPR and BQ showed the most pronounced decreases compared to the rate constant in the absence of scavengers, namely74\% (in the presence of IPR) and $37 \%$ (in the presence of $\mathrm{BQ}$ ) respectively. Although, the reactive species involved in the degradation of the pollutant in the case of the Ag-doped $\mathrm{TiO}_{2}$ are similar to those identified for the un-doped $\mathrm{TiO}_{2}$, the contribution of superoxide radicals is higher in the case of noble metal - doped $\mathrm{TiO}_{2}$. This behavior is due to the fact that $\mathrm{Ag}$ nano-particles are trapping sites for photo-generated electrons and concentration of generated superoxide radicals increases compared with un-doped $\mathrm{TiO}_{2}$.

Based on the quenching experiments results and Ag content influence on CP degradation efficiency corroborated with literature information it was proposed a mechanism of reactive species generation 
and their contribution to pollutant degradation by photocatalysis assisted by $\mathrm{Ag}$-doped $\mathrm{TiO}_{2}$ under UVVIS illumination, which is described by following equations:

$$
\begin{aligned}
& \mathrm{TiO}_{2}+h v \rightarrow e^{-}(\mathrm{CB})+h^{+}(\mathrm{VB}) \\
& \mathrm{Ag}_{n}+e^{-} \rightarrow \mathrm{Ag}_{n}^{-} \\
& \mathrm{Ag}^{-}+\mathrm{O}_{2} \rightarrow \mathrm{Ag}_{n}+\mathrm{O}_{2} \\
& \mathrm{Ag}^{-}+\mathrm{Ti}^{4+} \rightarrow \mathrm{Ag}_{n}+\mathrm{Ti}^{3+} \\
& \mathrm{h}^{+}+2 \mathrm{H}_{2} \mathrm{O} \rightarrow \mathrm{OH}_{\text {free }}(\text { in bulk solution })+\mathrm{H}_{3} \mathrm{O}^{+} \\
& \mathrm{CP}+\mathrm{OH}_{\text {free }} \mathrm{O}_{2}{ }^{-} \rightarrow \mathrm{CP} \text { Degradation Products } \\
& \mathrm{Ag}^{-}{ }^{-}+h^{+} \rightarrow \mathrm{Ag}_{n}
\end{aligned}
$$

Under UV-VIS illumination of Ag-doped $\mathrm{TiO}_{2}$, electrons are promoted to the conduction band (CB) and holes are generated in the valence band (VB) of $\mathrm{TiO}_{2}$ (Eq.7). The photo-generated electrons are transferred to surface Ag cluster, which behave like accumulation sites (Eq.8).As experimental results showed, better charges separation is assured by Ag concentration increases up to optimum content. The trapped electrons react even with adsorbed molecular oxygen or with titanium surface ions $\left(\mathrm{Ti}^{4+}\right)$ forming superoxide $\left(\mathrm{O}_{2}{ }^{-*}\right)$ reactive species and reactive surface center $\left(\mathrm{Ti}^{3+}\right)$, respectively, as is illustrated in Eqs. (9) and (10). Data reported in the literature showed that these reactions of trapped electrons slow down charge recombination and accelerate generation of superoxide ions and surface reactive centers [24]. On the other hand, the hydroxyl radicals levelalso increased, due to the increase of holes concentration implicated in their generation (Eq.11), as a consequence of electrons capture on Ag clusters. The main reactive species involved in $\mathrm{CP}$ degradation are free hydroxyl radicals (in bulk solution) and superoxide radicals (on catalyst surface) (Eq.12), as quenching experimental results showed. The possible oxidative conversion route is nucleophilic attack on chloroalkyl-side chain of pollutant as was reported in the case $\mathrm{Pt}$ or $\mathrm{Fe}$-doped $\mathrm{TiO}_{2}$ catalysts applied in the photocatalytic degradation of Ifosfamide, a structure isomer of CP [25, 29-31]. When Ag level overcomes the optimum content, the number of trapped electrons is high enough for Ag clusters to become recombination centers of holes. (Eq.13) and the CP degradation performance is detrimental affected, as the experimental results regarding the influence of $\mathrm{Ag}$ concentration on degradation efficiency showed.

\section{Conclusions}

$\mathrm{CP}$ degradation was studied using UV-VIS/Ag-doped $\mathrm{TiO}_{2}$ systems. Experimental results showed that $\mathrm{Ag}$ loading increase of up to $1.0 \%$ wt.content had a positive influence on the pollutant degradation efficiency $\left(\eta_{\mathrm{CP}}=99 \%\right)$. Enhanced photocatalytic activity of $\mathrm{Ag}$-doped $\mathrm{TiO}_{2}$ compared with un-doped $\mathrm{TiO}_{2}$ is a consequence of charges recombination inhibition, due to fact that nano-particles of $\mathrm{Ag}$ on $\mathrm{TiO}_{2}$ surface acts as electrons captors. As quenching experiments revealed, the main reactive species involved in CP photocatalytic degradation were free hydroxyl radicals and superoxide radicals for both catalyst, but $\mathrm{O}_{2}{ }^{-}$participation is more pronounced in the case of $\mathrm{Ag}$-doped $\mathrm{TiO}_{2}$ compared with undoped $\mathrm{TiO}_{2}$. It can be concluded that these reactive species together with reactive centre $\left(\mathrm{Ti}^{3+}\right)$ formed on the catalyst surface, as the proposed mechanism showed, are both responsible for the enhanced photocatalytic activity of Ag-doped $\mathrm{TiO}_{2}$. Experimental results proved that photocatalytic degradation under UV-VIS irradiation using Ag-doped $\mathrm{TiO}_{2}$ is an attractive alternative for cytostatic drugs like CP.

Acknowledgment: This work was realised with the support of Operational Programme Competitiveness 2014 - 2020, Project ID P_40_300, SMIS 105581, Subsidiary Contract $6537 / 27.04 .2018$. 


\section{References}

1.JOHNSON, A.C., M.D. JÜRGENS, R.J. WILLIAMS, K. KÜMMERER, A. KORTENKAMP, J.P. SUMPTER, Do cytotoxic chemotherapy drugs discharged into rivers pose a risk to the environment and human health? An overview and UK case study, J. Hydrol., 348(1-2), 2008, 167-175.

2.MARTÍN, J., D. CAMACHO-MUÑOZ, J.L. SANTOS, I. APARICIO, E. ALONSO, Simultaneous determination of a selected group of cytostatic drugs in water using high-performance liquid chromatography-triple-quadrupole mass spectrometry, J. Sep. Sci., 34(22), 2011, 3166-3177.

3.BUERGE, I.J., H.-R. BUSER, T. POIGER, M.D. MÜLLER, Occurrence and fate of the cytostatic drugs cyclophosphamide and ifosfamide in wastewater and surface waters, Environ. Sci. Technol., 40(23), 2006, 7242-7250.

4.TERNES, T.A., Occurrence of drugs in German sewage treatment plants and rivers, Water Res., 32(11), 1998, 3245-3260.

5.CALAMARI, D., E. ZUCCATO, S. CASTIGLIONI, R. BAGNATI, R. FANELLI, Strategic survey of therapeutic drugs in the rivers Po and Lambro in northern Italy, Environ. Sci. Technol., 37(7), 2003, 1241-1248.

6.ZUCCATO, E., S. CASTIGLIONI, R. FANELLI, Identification of the pharmaceuticals for human use contaminating the Italian aquatic environment, J. Hazard. Mater., 122(3), 2005, 205-209.

7.MOLDOVAN, Z., Occurrences of pharmaceutical and personal care products as micropollutants in rivers from Romania, Chemosphere, 64(11), 2006, 1808-1817.

8.PIECZYŃSKA, A., A. FISZKA BORZYSZKOWSKA, A. OFIARSKA, E.M. SIEDLECKA, Removal of cytostatic drugs by AOPs: A review of applied processes in the context of green technology, Crit. Rev. Env. Sci. Technol., 47(14), 2017, 1282-1335.

9.GARCIA-AC, A., R. BROSÉUS, S. VINCENT, B. BARBEAU, M. PRÉVOST, S. SAUVÉ, Oxidation kinetics of cyclophosphamide and methotrexate by ozone in drinking water, Chemosphere, 79(11), 2010, 1056-1063.

10.LUTTERBECK, C.A., E.L. MACHADO, K. KÜMMERER, Photodegradation of the antineoplastic cyclophosphamide: a comparative study of the efficiencies of UV/H2O2, UV/Fe2+/H2O 2 and UV/TiO2 processes, Chemosphere, 120, 2015, 538-546.

11.LIN, H.H.-H., A.Y.-C. LIN, Photocatalytic oxidation of 5-fluorouracil and cyclophosphamide via UV/TiO2 in an aqueous environment, Water Res., 48, 2014, 559-568.

12.LAI, W.W.-P., H.H.-H. LIN, A.Y.-C. LIN, TiO2 photocatalytic degradation and transformation of oxazaphosphorine drugs in an aqueous environment, J. Hazard. Mater., 287, 2015, 133-141.

13.POSTIGO, C., C. SIRTORI, I. OLLER, S. MALATO, M.I. MALDONADO, M.L. DE ALDA, D. BARCELÓ, Solar transformation and photocatalytic treatment of cocaine in water: kinetics, characterization of major intermediate products and toxicity evaluation, Appl. Catal., B, 104(1-2), 2011,37-48.

14.HAN, F., V.S.R. KAMBALA, M. SRINIVASAN, D. RAJARATHNAM, R. NAIDU, Tailored titanium dioxide photocatalysts for the degradation of organic dyes in wastewater treatment: a review, Appl. Catal., A, 359(1-2), 2009, 25-40.

15.SATO, S., R. NAKAMURA, S. ABE, Visible-light sensitization of TiO2 photocatalysts by wetmethod N doping, Appl. Catal., A, 284(1-2), 2005, 131-137.

16.ROCKAFELLOW, E.M., L.K. STEWART, W.S. JENKS, Is sulfur-doped TiO2 an effective visible light photocatalyst for remediation?, Appl. Catal., B, 91(1-2), 2009, 554-562.

17.CRISAN, M., A. BRAILEANU, M. RAILEANU, M. ZAHARESCU, D. CRISAN, N. DRAGAN, M. ANASTASESCU, A. IANCULESCU, I. NITOI, V.E. MARINESCU, Sol-gel S-doped TiO2 materials for environmental protection, J. Non-Cryst. Solids, 354(2-9), 2008, 705-711.

18.CRISAN, M., D. MARDARE, A. IANCULESCU, N. DRAGAN, I. NITOI, D. CRISAN, M. VOICESCU, L. TODAN, P. OANCEA, C. ADOMNITEI, Iron doped TiO2 films and their photoactivity in nitrobenzene removal from water, Appl. Surf. Sci., 455, 2018, 201-215. 
19.CRISAN, M., M. RAILEANU, N. DRAGAN, D. CRISAN, A. IANCULESCU, I. NITOI, P. OANCEA, S. SOMACESCU, N. STANICA, B. VASILE, Sol-gel iron-doped TiO2 nanopowders with photocatalytic activity, Appl. Catal., A, 504, 2015, 130-142.

20.NITOI, I., P. OANCEA, M. RAILEANU, M. CRISAN, L. CONSTANTIN, I. CRISTEA, UV-VIS photocatalytic degradation of nitrobenzene from water using heavy metal doped titania, J. Ind. Eng. Chem., 21, 2015, 677-682.

21.KLOSEK, S., D. RAFTERY, Visible light driven V-doped TiO2 photocatalyst and its photooxidation of ethanol, J. Phys. Chem. B, 105(14), 2001, 2815-2819.

22.BEHAR, D., J. RABANI, Kinetics of hydrogen production upon reduction of aqueous $\mathrm{TiO} 2$ nanoparticles catalyzed by $\mathrm{Pd} 0, \mathrm{Pt} 0$, or $\mathrm{Au} 0$ coatings and an unusual hydrogen abstraction; steady state and pulse radiolysis study, The Journal of Physical Chemistry B, 110(17), 2006, 8750-8755.

23.YAMAKATA, A., T.-A. ISHIBASHI, H. ONISHI, Water-and oxygen-induced decay kinetics of photogenerated electrons in $\mathrm{TiO} 2$ and Pt/TiO2: a time-resolved infrared absorption study, The Journal of Physical Chemistry B, 105(30), 2001, 7258-7262.

24.LIU, S., Z. QU, X. HAN, C. SUN, A mechanism for enhanced photocatalytic activity of silverloaded titanium dioxide, Catalysis Today, 93, 2004, 877-884.

25.OFIARSKA, A., A. PIECZYŃSKA, A.F. BORZYSZKOWSKA, P. STEPNOWSKI, E.M. SIEDLECKA, Pt-TiO2-assisted photocatalytic degradation of the cytostatic drugs ifosfamide and cyclophosphamide under artificial sunlight, Chemical Engineering Journal, 285, 2016, 417-427.

26.VAMATHEVAN, V., R. AMAL, D. BEYDOUN, G. LOW, S. MCEVOY, Photocatalytic oxidation of organics in water using pure and silver-modified titanium dioxide particles, Journal of Photochemistry and Photobiology A: Chemistry, 148(1-3), 2002, 233-245.

27.NI, M., M.K. LEUNG, D.Y. LEUNG, K. SUMATHY, A review and recent developments in photocatalytic water-splitting using $\mathrm{TiO} 2$ for hydrogen production, Renewable and Sustainable Energy Reviews, 11(3), 2007, 401-425.

28.SALVADOR, P., On the nature of photogenerated radical species active in the oxidative degradation of dissolved pollutants with $\mathrm{TiO} 2$ aqueous suspensions: a revision in the light of the electronic structure of adsorbed water, The Journal of Physical Chemistry C, 111(45), 2007, 1703817043.

29.CONSTANTIN, L.A., M.A. CONSTANTIN, I. NITOI, L.F. CHIRIAC, L.F. PASCU, T. GALAON, Possible pathway for ifosfamide degradation via Fe-TiO2 assisted photo catalysis, Rev. Chim., 69(11), 2018, 3234-3237.

30.CONSTANTIN, L.A., I. CRISTEA, I. NITOI, M.A. CONSTANTIN, G. NECHIFOR, Kinetics of Cyclophosphamide and Ifosfamide Degradation from Aqueous System via TiO, Rev. Chim., 68(8), 2017, 1690-1694.

31.CONSTANTIN, L.A., I. NITOI, I. CRISTEA, P. OANCEA, Kinetics of 5-fluorouracil degradation by heterogenous TiO2 photocatalysis, Rev. Chim., 67(8), 2016, 1447-1450.

Manuscript received: 19.12.2019 